\title{
Occurrence of Enterococcus spp. in poultry in Poland based on 2014-2015 data
}

\author{
BEATA DOLKA, MARIOLA GOŁĘBIEWSKA-KOSAKOWSKA*, KRZYSZTOF KRAJEWSKI*, \\ PIOTR KWIECIŃSKI**, TOMASZ NOWAK ${ }^{* *}$, JAROS $Ł A W ~ S Z U B S T A R S K I^{* * * *}$, \\ JAROSŁAW WILCZYŃSKI***, PIOTR SZELESZCZUK
}

\author{
Department of Pathology and Veterinary Diagnostics, Faculty of Veterinary Medicine, \\ Warsaw University of Life Sciences - SGGW, Nowoursynowska 159c St., 02-776 Warsaw, Poland \\ *Vetdiagnostica, Otorowo 30, 86-050 Solec Kujawski, Poland \\ **Vet-Lab Brudzew, Turkowska 58c St., 62-720 Brudzew, Poland \\ ***Lab-Vet, Okrężna 8 St., 62-080 Tarnowo Podgórne, Poland \\ ****SLW Biolab, Grunwaldzka 62 St., 14-100 Ostróda, Poland
}

\section{Dolka B., Gołębiewska-Kosakowska M., Krajewski K., Kwieciński P., Nowak T., Szubstarski J., Wilczyński J., Szeleszczuk P. \\ Occurrence of Enterococcus spp. in poultry in Poland based on 2014-2015 data}

\section{Summary}

Bacteria of the genus Enterococcus are mainly commensals building natural microflora in the digestive tract of birds and mammals. They belong to the potentially pathogenic microorganisms. Among poultry, infections caused by enterococci were reported in chickens, turkeys, ducks and ostriches. The aim of this study was to evaluate the occurrence of enterococci in poultry in Poland, including identification of enterococcus species composition and determination of the age of birds. The analysis was based on data obtained from 2014-2015 from Division of Avian Diseases at Warsaw University of Life Sciences-SGGW and four veterinary laboratories in Poland: Lab-Vet, Tarnowo Podgórne; SLW Biolab, Ostróda; Vetdiagnostica, Solec Kujawski; Vet-Lab Brudzew. Seven enterococcal species were isolated from broiler chickens (CB), commercial layers (CL), and broiler breeder flocks (BB), nine from all poultry types (chickens, turkey, ducks and geese). The most often isolated enterococci from CB were E. faecalis $(57 \%)>$ E. cecorum $(7 \%)>$ E. faecium $(5.2 \%)>E$. hirae $(3.6 \%)>$ E. gallinarum $(2.5 \%)>$ E. casseliflavus $(0.7 \%)>$ E. durans $(0.2 \%)$. Seven Enterococcus species were isolated from sources associated with poultry, most often $\mathbf{E}$. faecalis $>E$. faecium $>E$. cecorum $>E$. hirae. The differences in the occurrence of particular enterococcal species were observed between CB, BB and CL. The mean age at the time of isolation of E. cecorum was approx.: 3.6 weeks in $\mathrm{CB}, 27.5$ weeks in $\mathrm{BB}, 33.3$ weeks in CL, 12.9 weeks in turkeys, 3.6 weeks in ducks, 39.5 weeks in geese. $E$. faecalis and $E$. faecium dominated in samples obtained from hatching eggs, dead-in-shell embryos and from samples related to poultry environment.

In conclusion, this study indicates the high prevalence of bacteria of the Enterococcus genus in poultry. The present findings demonstrate the differences in Enterococcus species between poultry groups, including with regard to age. In total 10 enterococcal species (E. faecalis, E. cecorum, E. hirae, E. faecium, E. gallinarum, E. casseliflavus, E. durans, E. avium, E. thailandicus, E. aquimarinus) were detected in poultry, poultry environmental samples, hatching eggs and dead-in-shell embryos. Enterococcus faecalis and E. cecorum were found in all above-mentioned sources.

Keywords: Enterococcus species, poultry, enterococci

Bacteria of the Enterococcus genus constitute the natural intestinal microflora of mammals and birds, and are ubiquitous in the environment. Until today, 53 Enterococcus species and 2 subspecies have been recognized. In the last 6 years (2010-2016) 13 species and 2 subspecies were described. Among all known enterococci, only a few species are isolated from birds, mainly: E. faecalis, E. faecium, E. hirae, E. cecorum, E. durans, E. avium, E. casseliflavus, E. gallinarum,
E. raffinosus and E. columbae (from pigeons), E. alcedinis (from common kingfishers). The composition of the enterococcal intestinal flora varies with the age of birds. Moreover, changes in the enterococcal species composition are observed. In 1-day-old chicks E. faecalis and E. faecium were found mainly in intestines, while E. durans in the crop. According to Devriese et al. (5) the earliest occurrence of E. cecorum in the digestive tract of chickens was recorded at the age of 
3-4 weeks. Enterococcus cecorum was predominant enterococcal component in the crop and intestines in chickens by 12 weeks of age. However, Enterococcus durans could be found in the crop of 1-day-old chicks, later (at an age of 3-4 weeks) in the intestines (5). Enterococci are potentially pathogenic bacteria with the ability to cause serious diseases in birds. So far, infections caused by Enterococcus spp. have been described in chickens, turkeys, ducks, ostriches, pigeons and canaries. Among 53 enteroccocal species, E. faecalis, E. cecorum, E. hirae, E. faecium and $E$. durans have the most crucial role in avian pathology. Enterococcus faecalis has been described as a cause of omphalitis, endocarditis, meningitis, fibrinous arthritis and/or tenosynovitis. Moreover, E. faecalis may participate in the etiology of Pulmonary Hypertension Syndrome (PHS) in broilers (17). Investigations by Landman et al. (11) confirmed that arthropathic and amyloidogenic E. faecalis strains have the potential to induce amyloid arthropathy and chronic infections in brown layers. Enterococcus faecalis has also been shown to be involved in First-Week Mortality Syndrome (FWM) in layers (14). However, E. cecorum may cause enterococcal spondylitis, femoral head necrosis, arthritis. Infection with E. cecorum can constitute a serious health problem, usually for commercial broiler chickens and broiler breeder flocks $(2,7,12)$. Recently, E. cecorum-associated disease was reported in Pekin ducks and in racing pigeons (9). Other species such as E. hirae and E. durans may cause endocarditis and encephalomalacia in chickens. There are differences in age-related susceptibility to strains causing endocarditis. Septicaemia and endocarditis caused by E. durans seem to be limited to mature birds, whereas infections with $E$. hirae appear to include young chickens $(3,18)$. Enterococcus-associated encephalomalacia has been noted in 1-week-old to 2-week-old broilers and commercial layers $(1,3,4)$. In the literature there is still not enough information which enterococcal species are associated with certain birds.

The aim of this study was to evaluation the prevalence of Enterococcus spp. in poultry in Poland with regard to species composition.

\section{Material and methods}

The analysis is based on data from 01.01.2014-01.07.2015 collected in Poland from the following veterinary laboratories: Division of Avian Diseases, Department of Pathology and Veterinary Diagnostics, Faculty of Veterinary Medicine, WULS-SGGW, Warsaw; Lab-Vet, Tarnowo Podgórne (Greater Poland); SLW Biolab, Ostróda (Warmia-Masuria); Vetdiagnostica, Solec Kujawski (Kuyavia-Pomerania); Vet-Lab Brudzew (Greater Poland). Materials mainly included samples from affected birds (tissues, swabs, dead-in-shell embryos) collected during standard diagnostic necropsies and from samples related to poultry environment (e.g. feed, water, control swabs from surfaces, chick transport papers with meconium, fluff from hatchery cham- bers). Bacteriological tests and identification methods were carried out in accordance with the diagnostic procedures applied in individual laboratories. The samples were directly plated onto blood agar containing 5\% sterile bovine or sheep blood, or CNA agar with 5\% sheep blood, and onto agar containing esculin (Enterococcosel Agar or KAA agar). All agar plates were incubated microaerofically at $37^{\circ} \mathrm{C}$ for $24 \mathrm{~h}$ after which culture results were evaluated based upon colony morphology. Species identification was based on biochemical tests (API rapid ID 32 STREP, bioMérieux, France), or MALDI-TOF and PCR (8).

\section{Results and discussion}

During the 2014-2015 period a total of 2828 Enterococcus spp. were retrieved from animal sources, from which $82.6 \%(2337 / 2828)$ were retrieved from poultry, $8.8 \%(250 / 2828)$ from a poultry production environment, $2.5 \%$ (71/2828) from hatching eggs and deadin-shell embryos.

The most numerous of enterococcal strains originated from chickens $(73.7 \%$; 1723/2337), including $61.2 \%(1431 / 2337)$ from commercial broiler chickens (CB), 7.2\% (168/2337) from commercial layers (CL), $3.6 \%(85 / 2337)$ from broiler breeder chickens, and $1.7 \%(39 / 2337)$ from other chickens (no data on the flock type). Among other poultry species, strains originated from turkeys $(23.4 \% ; 548 / 2337)$, geese $(2.1 \%$; $50 / 2337)$ and ducks $(0.7 ; 16 / 2337)$. Similarly to other studies (15), in our study the most positive samples for enterococci were in broilers. In poultry, 9 of the most frequent identified species were $E$. faecalis $(42.5 \%)>$ E. cecorum $(7.9 \%)>E$. faecium $(4.4 \%)>$ E. hirae $(2.7 \%)>E$. gallinarum $(2.2 \%)>E$. casseliflavus $(0.6 \%)>$ E. durans $(0.2 \%)>E$. avium $(0.16 \%)$ $>$ E. aquimarinus $(0.04 \%)$. However, a number of isolates $(39.3 \%)$ were not recognized to the species level. We found that E. faecalis seems to be the dominant enterococcal species in poultry. Our results were consistent with the literature (15). In opposition to other authors, we isolated E. cecorum more often, and more rarely E. faecium, E. hirae, E. gallinarum. Data analysis with respect to the specific group of poultry demonstrated the prevalence of 7 different Enterococcus species among broiler chickens (CB), commercial layers (CL), and broiler breeders (BB). All mentioned groups were positive for 5 species: E. faecalis, E. cecorum, E. hirae, E. gallinarum, E. casseliflavus. According to other authors, there are differences in Enterococcus species composition between broilers and layers (20), which was also confirmed by our results. In the present study, E. avium was not seen in $\mathrm{CB}$, and $E$. faecium in $\mathrm{BB}, E$. durans in CL (Fig. 1 A, B, C). The occurrence of enterococcal species in turkeys and waterfowl was shown in Fig. 1 D, E, F. According to Kizerwetter-Świda and Binek (10), enterococci dominate in the caecal flora of 20-day-old embryos and 1-day-old chicks. Some Enterococcus species found in 1-day-old chicks may 
A) Broiler chickens (CB)

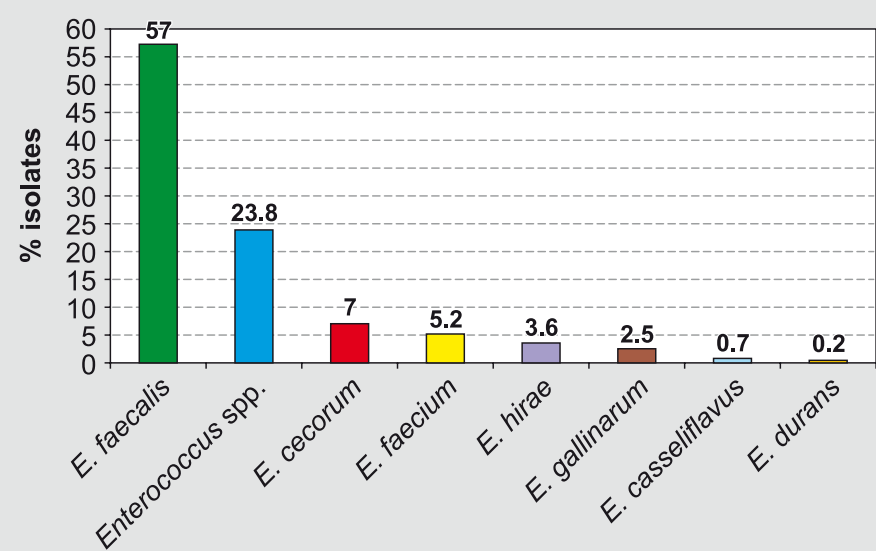

C) Commercial layers (CL)

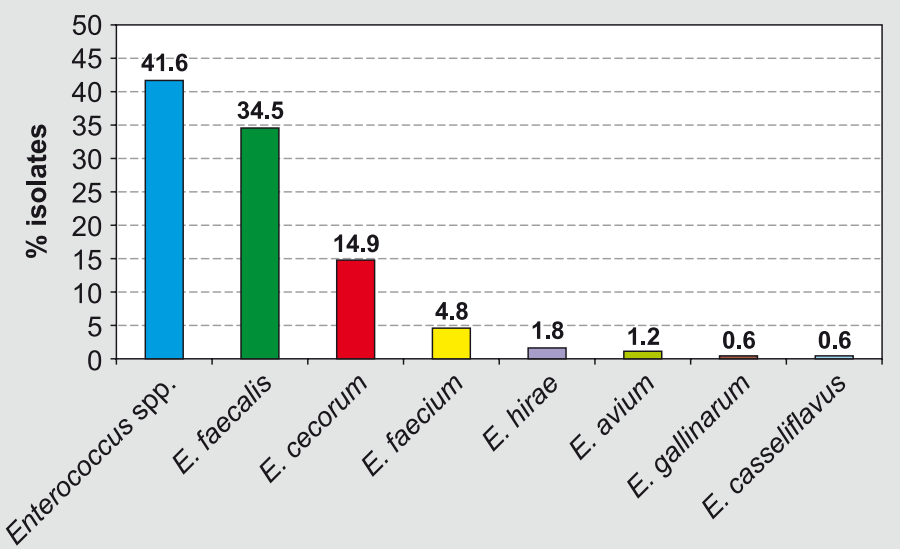

E) Geese (G)

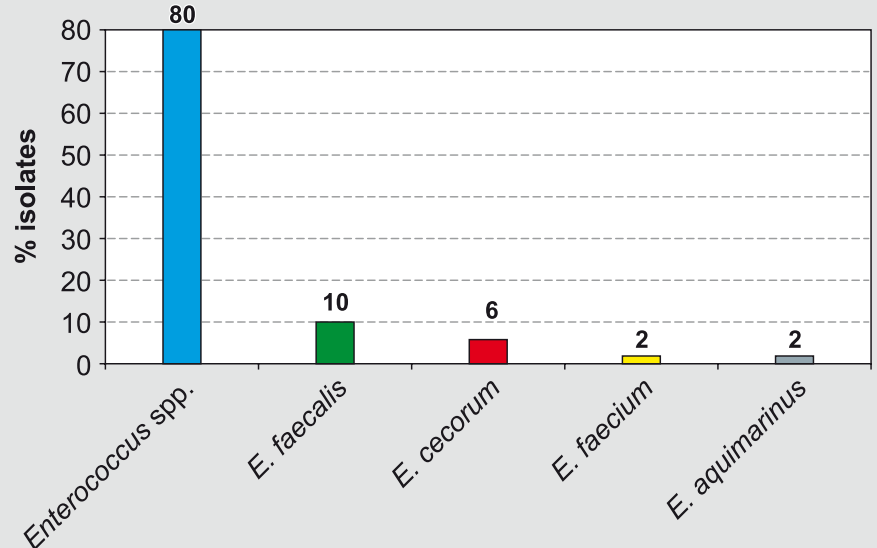

\section{B) Broiler breeders (BB)}

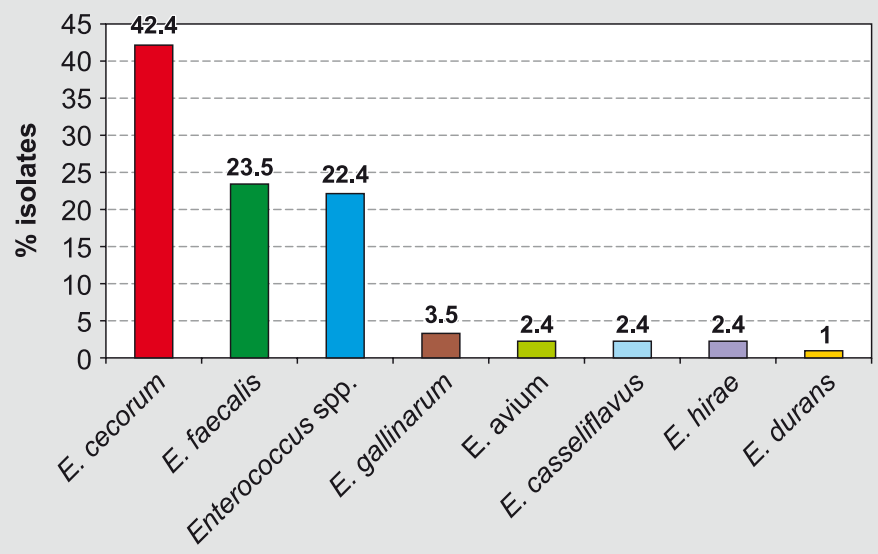

D) Turkeys (T)

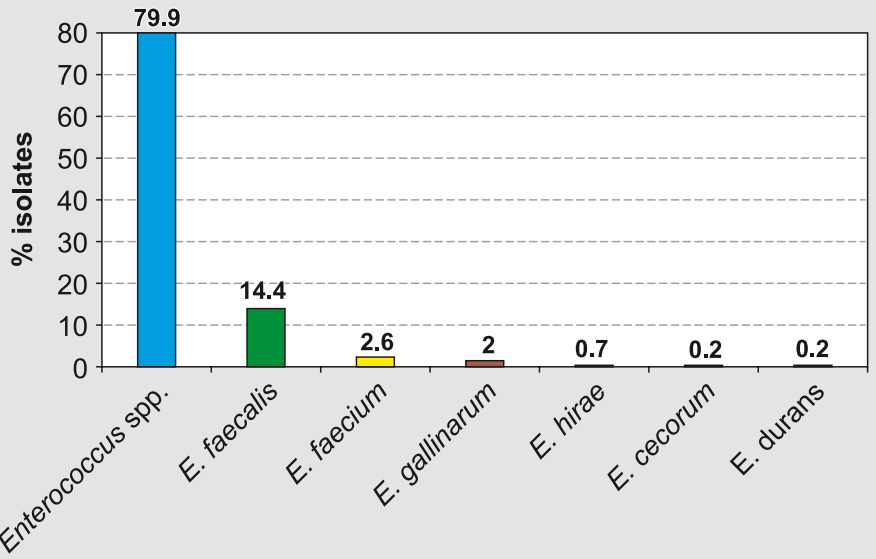

F) Ducks (D)

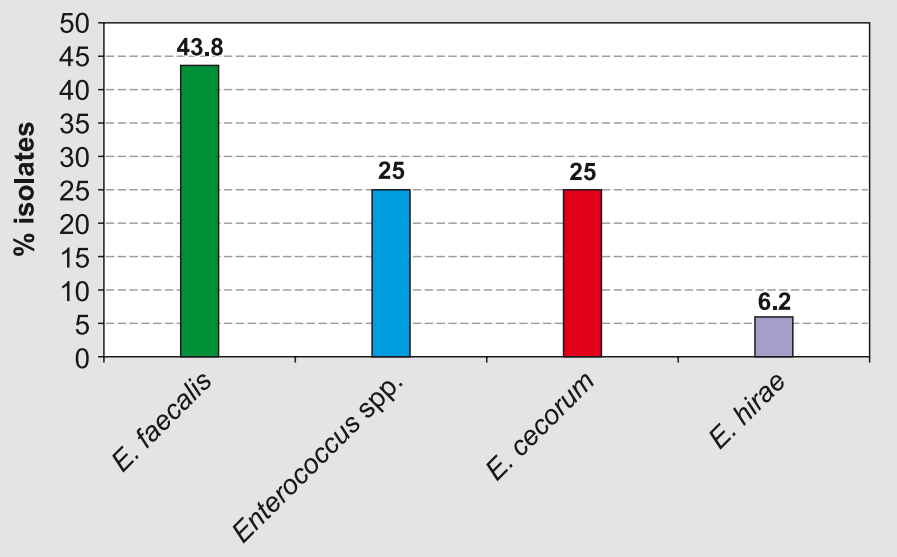

Fig. 1. A-F Percentage of Enterococcus species isolated from different poultry

be absent (or at lower rate) in older chickens (5). Under certain conditions, the presence of Enterococcus species non-typical for chicken's age, outside the natural habitat in organisms, may promote infection. Tankson et al. (16) proved that $E$. faecalis may be isolated from the heart and lungs of healthy chickens starting from the $17^{\text {th }}$ day of incubation, and could become pathogenic if predisposing factors prevail. Table 1 shows the mean age of poultry at isolation of Enterococcus spp. from diagnostic cases. Olsen et al. (13) showed that $15 \%$ of the chicks may be positive for $E$. faecalis when hatching started, and $70 \%$ when sampled $24 \mathrm{~h}$ after hatching. We found that the most $E$. faecalis was isolated from 1-day-old chicks (CB 30.4\%; BB 62.5\%; CL $59.2 \%$; turkeys $34 \%$; geese $33.3 \%$; ducks $57.1 \%$ ). Out of 7 enterococci identified from hatching eggs, dead-in-shell embryos, Enterococcus faecalis and E. faecium were recognized more consistently (Fig. 2). Similarly, other authors isolated E. faecalis (then E. faecium) mainly from broilers between 1 and 5 days of age $(15,19)$. We found that $E$. cecorum may be seen in all groups of poultry, usually after 3.6 weeks of 
Tab. 1. The mean age of poultry at isolation of Enterococcus spp. from diagnostic cases

\begin{tabular}{|c|c|c|c|c|c|c|}
\hline \multirow{3}{*}{$\begin{array}{l}\text { Enterococcus } \\
\text { species }\end{array}$} & \multicolumn{6}{|c|}{ Mean age of birds (days/weeks) } \\
\hline & \multicolumn{3}{|c|}{ Chickens } & \multirow{2}{*}{ Turkeys } & \multirow{2}{*}{ Ducks } & \multirow{2}{*}{ Geese } \\
\hline & CB & BB & CL & & & \\
\hline E. faecalis & 2.1 days & $\begin{array}{l}84.4 \text { days } \\
\text { (12 weeks) }\end{array}$ & $\begin{array}{l}64.2 \text { days } \\
\text { ( } 9 \text { weeks) }\end{array}$ & $\begin{array}{l}28.2 \text { days } \\
\text { (4 weeks) }\end{array}$ & 1.4 day & $\begin{array}{l}124.3 \text { days } \\
\text { (18 weeks) }\end{array}$ \\
\hline E. durans & 3.3 days & $\begin{array}{c}63 \text { days } \\
\text { (9 weeks) }\end{array}$ & ND & $\begin{array}{c}59 \text { days } \\
\text { (8 weeks) }\end{array}$ & ND & ND \\
\hline E. gallinarum & 3.4 days & 1 day & 1 day & $\begin{array}{l}19.1 \text { days } \\
\text { ( } 3 \text { weeks) }\end{array}$ & ND & ND \\
\hline E. hirae & 12.3 days & 4 days & $\begin{array}{l}26.7 \text { days } \\
\text { (4 weeks) }\end{array}$ & $\begin{array}{c}42 \text { days } \\
\text { (6 weeks) }\end{array}$ & 3 days & ND \\
\hline E. faecium & 3.5 days & ND & $\begin{array}{l}154.4 \text { days } \\
\text { (22 weeks) }\end{array}$ & $\begin{array}{l}30.2 \text { days } \\
\text { (4 weeks) }\end{array}$ & ND & 3 years \\
\hline E. cecorum & $\begin{array}{c}25.4 \text { days } \\
\text { (3.6 weeks) }\end{array}$ & $\begin{array}{c}193.6 \text { days } \\
\text { (27.5 weeks) }\end{array}$ & $\begin{array}{c}232.8 \text { days } \\
\text { (33.3 weeks) }\end{array}$ & $\begin{array}{c}90.1 \text { days } \\
\text { (12.9 weeks) }\end{array}$ & $\begin{array}{c}25.1 \text { days } \\
\text { (3.6 weeks) }\end{array}$ & $\begin{array}{c}276.3 \text { days } \\
\text { (39.5 weeks) }\end{array}$ \\
\hline
\end{tabular}

Explanations: CB (commercial broiler chickens); BB (broiler breeders); CL (commercial layers); ND (no data)

age depending on the purpose of production (Tab. 1). Wilczyński et al. (19) isolated 4 enterococci (E. cecorum, E. faecalis, E. hirae, E. faecium) in older broilers (5 days up to 6 weeks old), and E. cecorum was the dominant species.

A total of 7 enterococcal species were retrieved from poultry production environmental samples (Fig. 3). Enterococcus faecalis (65.6\%) and E. faecium (13.6\%) were the most frequently isolated. Our results were consistent to Hayes et al. (6) who isolated E. faecalis $(>50 \%)$ and E. faecium ( $>30 \%$ ) from the poultry production environment, while 5 other species (E. gal-

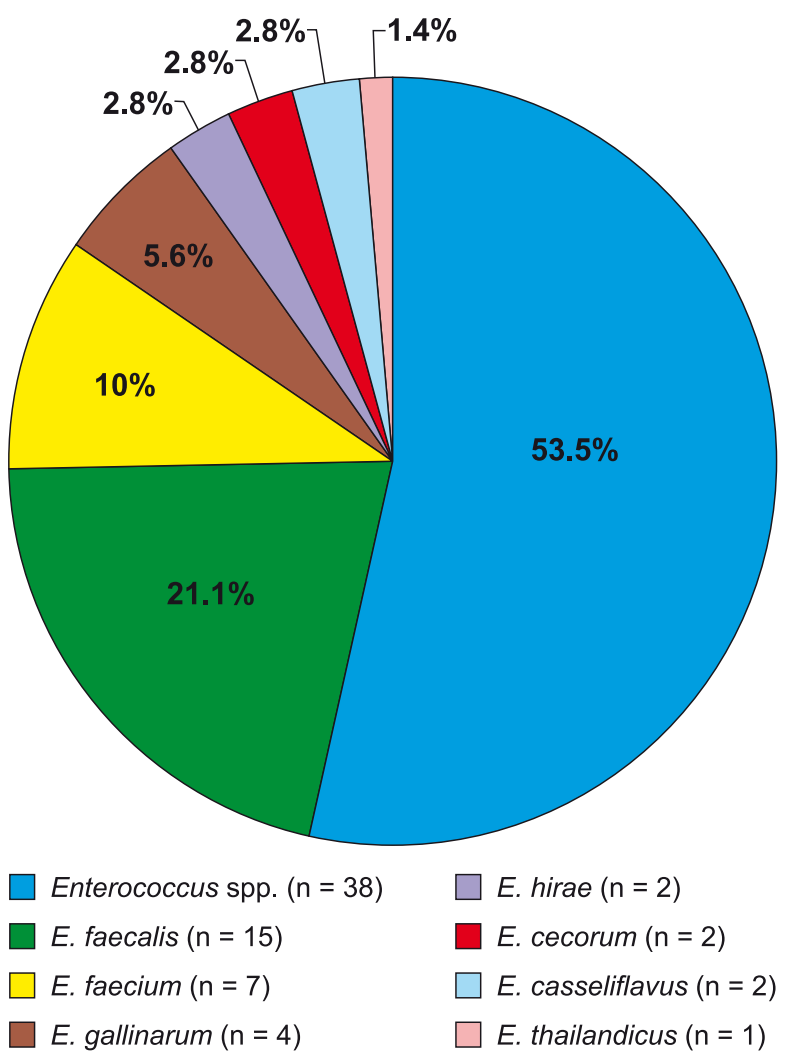

Fig. 2. Percentage of Enterococcus species isolated from hatching eggs and dead-in-shell embryos linarum $>$ E. hirae $>$ E. durans $>$ E. casseliflavus, E. avium) were less isolated. In opposition to above authors, we found E. cecorum (6\%) in environmental samples.

In conclusion, this study indicates the high prevalence of bacteria of the Enterococcus genus in poultry. The present findings demonstrate the differences in Enterococcus species between poultry groups, including with regard to age. In total 10 enterococcal species (E. faecalis, E. cecorum, E. hirae, E. faecium, E. gallinarum, E. casseliflavus, E. durans, E. avium, E. thailandicus, E. aquimarinus) were detected in

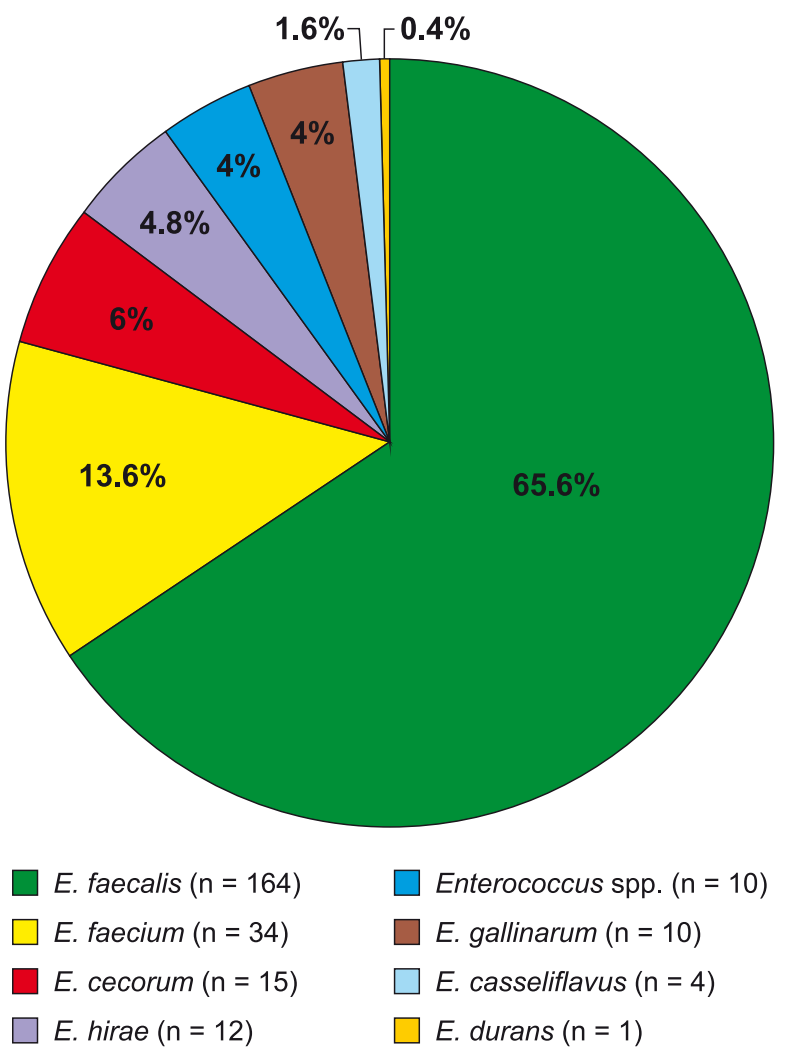

Fig. 3. Percentage of Enterococcus species isolated from environmental samples 
poultry, poultry environmental samples, hatching eggs and dead-in-shell embryos. Enterococcus faecalis and E. cecorum were found in all above-mentioned sources.

\section{References}

1. Abe Y., Nakamura K., Yamada M., Yamamoto Y.: Encephalomalacia with Enterococcus durans infection in the brain stem and cerebral hemisphere in chicks in Japan. Avian Dis. 2006, 50, 139-141.

2. Borst L. B., Suyemoto M. M., Sarsour A. H., Harris M. C., Martin M. P., Strickland J. D., Oviedo E. O., Barnes H. J.: Pathogenesis of Enterococcal Spondylitis Caused by Enterococcus cecorum in Broiler Chickens. Vet. Pathol. 2016 Aug 10. pii: 0300985816658098. [Epub ahead of print]

3. Chadfield M. S., Bojesen A. M., Christensen J. P., Juul-Hansen J., Nielsen S. S., Bisgaard M.: Reproduction of sepsis and endocarditis by experimental infection of chickens with Streptococcus gallinaceus and Enterococcus hirae. Avian Pathol. 2005, 34, 238-247.

4. Chamanza R., Fabri T. H., van Veen L., Dwars R. M.: Enterococcus-associated encephalomalacia in one-week-old chicks. Vet. Rec. 1998, 143, 450-451.

5. Devriese L. A., Hommez J., Wijfels R., Haesebrouck F.: Composition of the enterococcal and streptococcal intestinal flora of poultry. J. Appl. Bacteriol. 1991, 71, 46-50.

6. Hayes J. R., English L. L., Carr L. E., Wagner D. D., Joseph S. W.: Multipleantibiotic resistance of Enterococcus spp. isolated from commercial poultry production environments. Appl. Environ. Microbiol. 2004, 70, 6005-6011.

7. Herdt De P., Defoort P., Steelant Van J., Swam H., Tanghe L., Goethem Van S., Vanrobaeys $M$ : : Enterococcus cecorum osteomyelitis and arthritis in broiler chickens. Vlaams Diergen. Tijds. 2008, 78, 44-48.

8. Jackson C. R., Fedoka-Cray P. J., Barett J. B.: Use of a genus- and speciesspecific multiplex PCR for identication of enterococci. J. Clin. Microbiol. 2004, 42, 3558-3565.

9. Jung A., Teske L., Rautenschlein S.: Enterococcus cecorum infection in a racing pigeon. Avian Dis. 2014, 58, 654-658.
10. Kizerwetter-Świda M., Binek M.: Bacterial microflora of the chicken embryos and newly hatched chicken. J. Anim. Feed. Sci. 2008, 17, 224-232.

11. Landman W. J. M., Mekkes D. R., Chamanza R., Doornenbal P., Gruys E.: Arthropathic and amyloidogenic Enterococcus faecalis infections in brown layers: a study on infection routes. Avian Pathol. 1999, 28, 545-557.

12. Makrai L., Nemes C., Simon A., Ivanics E., Dudás Z., Fodor L., Glávits R.: Association of Enterococcus cecorum with vertebral osteomyelitis and spondylolisthesis in broiler parent chicks. Acta Vet. Hung. 2011, 59, 11-21.

13. Olsen R. H., Christensen H., Bisgaard M.: Transmission and genetic diversity of Enterococcus faecalis during hatch of broiler chicks. Vet. Microbiol. 2012, $160,214-221$.

14. Olsen R. H., Frantzen C., Christensen H., Bisgaard M.: An Investigation on First-Week Mortality in Layers. Avian Dis. 2012, 56, 51-57.

15. Stępień-Pyśniak D., Marek A., Banach T., Adaszek Ł., Pyzik E., Wilczyński J., Winiarczyk S.: Prevalence and antibiotic resistance of Enterococcus strains isolated from poultry. Acta Vet. Hung. 2016, 64, 148-163.

16. Tankson J. D., Thaxton J. P., Vizzier-Thaxton Y.: Bacteria in heart and lungs of young chicks. J. Appl. Microbiol. 2002, 92, 443-450.

17. Tankson J. D., Thaxton J. P., Vizzier-Thaxton Y.: Pulmonary Hypertension Syndrome in Broilers Caused by Enterococcus faecalis. Infect. Immun. 2001 $69,6318-6322$

18. Velkers F. C., van de Graaf-Bloois L., Wagenaar J. A., Westendorp S. T., van Bergen M. A., Dwars R. M., Landman W. J.: Enterococcus hirae-associated endocarditis outbreaks in broiler flocks: clinical and pathological characteristics and molecular epidemiology. Vet. Q. 2011, 31, 3-17.

19. Wilczyński J., Wystalska D.: Lekowrażliwość bakterii izolowanych od chorych kurcząt brojlerów pochodzących z ferm zlokalizowanych w województwie wielkopolskim. Cz. II. Enterococcus spp. Polskie Drobiarstwo 2016, 2, 52-57.

20. Yoshimura H., Ishimaru M., Endoh Y. S., Kojima A.: Antimicrobial susceptibilities of enterococci isolated from faeces of broiler and layer chickens. Lett. Appl. Microbiol. 2000, 31, 427-432.

Corresponding author: Beata Dolka (DVM, PhD), Nowoursynowska 159c, 02-776 Warsaw, Poland; e-mail: beata_dolka@sggw.pl 